\title{
Penggunaan Instrumen Cello Dalam Langgam Jawa
}

\author{
Sudarno 1
}

\begin{abstract}
Keroncong music is the result of a mixture of Portuguese culture and Indonesian culture around the year 1498. Java Javanese style which is one part of keroncong music develops well in Java as a form of community creativity. In 1934 was used pitchicato cello instrument that is picked the technique of strumming with fingers, by Tjok Shinsu. The cello instrument in its native country is a string instrument, by the Indonesians being transformed into a string instrument now known as "cello keroncong". Thanks to the creativity of the artists keroncong, then came the form of Langgam Jawa Keroncong, because according to Gesang that Langgam Jawa was born in 1950. While the Javanese Gamelan affects the original Keroncong, Macapat leads to the verses in Keroncong Langgam introduced by Gesang. The style of singing keroncong with Java elements is usually not displayed in the notation. The phenomenon is very interesting to explore further about the use of cello instruments in Langgam Keroncong. Research conducted with the object uses qualitative methods that rely on direct observation in the field in the pattern of cello instrument play. During the play Langgam Jawa the cello instrument plays a pattern of kendangan. The instrument gives an accentuation that gives the color of its own voice in a dish. The characteristic that stands out in Keroncong Javanese Langgam is located in the cello instrument game because in the form of the game imitate ciblon kendang. According to its function cello in Langgam Jawa Keroncong play a role as ritmis. The role of the cello instrument is the same as the kendang instrument that acts as a rhythm holder having the authority to carry the direction of the song to be performed, such as using ankle rhythm or double, or in karawitan called weled and rangkep.
\end{abstract}

Keywords: Cello Instrument, Style Pattern, Java Langgam

\begin{abstract}
Abstrak
Musik keroncong merupakan hasil percampuran budaya Portugis dan budaya Indonesia sekitar tahun 1498. Langgam Jawa yang merupakan salah satu bagian dari musik keroncong berkembang dengan baik di pulau Jawa sebagai bentuk kreativitas masyarakatnya. Pada tahun 1934 dipergunakanlah instrumen cello yang dipetik secara pizzicato yaitu teknik memetik alat musik gesek dengan menggunakan jari, oleh Tjok Shinsu. Alat musik cello yang di negeri asalnya merupakan alat musik gesek tersebut, oleh orang Indonesia dirubah menjadi alat musik petik yang kini dikenal sebagai "cello keroncong". Berkat kreatifitas para seniman keroncong, maka lahirlah bentuk Langgam Jawa Keroncong, karena menurut Gesang bahwa Langgam Jawa lahir tahun 1950.
\end{abstract}

\footnotetext{
${ }^{1}$ Staf Pengajar di Jurusan Etnomusikologi FSP ISI Yogyakarta
} 
Sementara Gamelan Jawa mempengaruhi Keroncong Asli, Macapat mengarah pada bait-bait dalam Langgam Keroncong yang diperkenalkan oleh Gesang. Gaya menyanyi keroncong dengan elemen Jawa biasanya tidak ditampilkan dalam notasi. Fenomena tersebut sangat menarik untuk ditelaah lebih jauh tentang penggunaan instrumen cello dalam Langgam Keroncong. Penelitian yang dilakukan dengan obyek tersebut mempergunakan metode kualitatif yang mengandalkan observasi secara langsung di lapangan dalam pola permainan instrumen cello.

Selama memainkan Langgam Jawa instrumen cello memainkan pola kendangan. Instrumen tersebut memberikan aksentuasi yang memberikan warna suara tersendiri dalam suatu sajiannya. Ciri khas yang menonjol dalam Langgam Jawa Keroncong yaitu terletak pada permainan instrumen cello karena dalam bentuk permainannya menirukan kendang ciblon. Menurut fungsinya cello dalam Langgam Jawa Keroncong memegang peranan sebagai ritmis. Peranan instrumen cello sama dengan instrumen kendang yang berperan sebagai pemegang irama yang mempunyai wewenang untuk mebawa arah lagu yang akan dibawakan seperti mempergunakan irama engkel atau dobel, atau dalam karawitan disebut dengan weled dan rangkep.

Kata Kunci: Instrumen Cello, Gaya Permainan, Langgam Jawa

\section{Pendahuluan}

Kelahiran musik keroncong di Indonesia memiliki latar belakang multi kultural pada spectrum yang lebih luas pada sejarah dunia, yang telah dimulai semenjak kedatangan para pelaut Portugis dalam perjalanannya menuju Timur, melalui Afrika Selatan, Semenanjung Arab, Goa, Malaka, dan Maluku dalam rangka mencari rempah-rempah. Mereka juga memperkenalkan budaya mereka, dalam hal ini adalah musik dan tarian Moresco serta Cafrinho. Musik tersebut dengan gitar cavaquinho yang mereka bawa selama perjalanan karena ukurannya yang kecil serta mudah dibawa. Pertama ke Maroko, pada 1582 melalui Madeira yang kemudian disebut braguinha, sebagai gitar yang berasal dari daerah Braga di Portugal. Di Brasil, instrument ini disebut machette, biasanya dipergunakan untuk mengiringi tarian para imigran dari Portugis. Sementara di kepulauna Karibia disebut sebagai cuatro, karena memiliki empat buah dawai. Gitar Portugis cavaquinho dipercaya mencapai Hawaai dan Polynesia, dimana disebut penduduk setempat sebagai ukulele, yang artinya secara harfiah "jumping fingers" (jari yang menari), dinamai sesuai dengan cara memainkannya.

Popularitas istilah Hawaai, ukulele memberikan tanda bahwa cavaquinho telah dibawa orang melewati Oceania dan Polynesia sebelum merambah bagian dunia lain termasuk Pulau Maluku dan Kampung Tugu sekitar abad tujuh belas. Hingga pada abad duapuluh, saat 
cavaquinho direvitalisasi di Portugal setelah sekian lama menghilang, sementara itu tetap dikenal di seluruh dunia sebagai ukulele.

Istilah Indonesianya sendiri mungkin saja merupakan onomatopea/tiruan bunyi "crong”, yang merupakan suara khas dari musik keroncong, atau secara etimologis berasal dari krincing rebana yang merupakan musik pengiring tarian Moresco. Ahli membuat alat musik keroncong adalah para pembuat gitar kampung tugu dan mereka memproduksi tiga macam gitar dengan lima dawai dalam berbagai ukuran yang disebut dengan prounga, macina dan jitera. Semua alat musik tersebut memiliki dawai tengah yang lebih besar disebut bordang dan dimainkan bersama dalam ansambel.

Dalam perkembangan lebih lanjut, pembuat gitar kampung tugu melakukan modifikasi alat musik keroncong kedalam cuk (ukulele pertama, atau jitera empat dawai), cak (ukulele kedua atau prounga dengan tiga dawai), dan macina lima dawai sebagai adaptasi mandolin dengan kualitas etnis Keroncong menurut Ensiklopedi (2009: 3) menjelaskan bahwa akar keroncong berasal dari sejenis musik Portugis yang dikenal sebagai fado, diperkenalkan oleh para pelaut dan budak kapal niaga bangsa itu sejak abad ke-16 ke Nusantara. Awalnya, fado dibawakan oleh para budak dari Afrika yang masuk ke Portugis, kemudian berbaur dengan budaya Moor dari Afrika dan menjadi musik yang dikenal dengan nama Moresco. Dari daratan India (Goa) masuklah musik tersebut pertama kali di Malaka dan kemudian dimainkan oleh para budak dari Maluku, melemahnya pengaruh Portugis pada abad ke-17 di Nusantara tidak dengan serta-merta berarti hilang pula musik jenis ini. Bentuk musik moresco, yang diiringi oleh alat musik dawai, dan berkembangan di sekitar kampung Tugu di daerah Semper, kecamatan Koja Jakarta Utara, karena hal tersebut maka musiknya disebut juga keroncong Tugu. Bentuk musik keroncong Tugu sangat dipengaruhi oleh musik Portugis, biasanya dimainkan untuk mengiringi kebaktian di gereja, acara pesta natal dan pergantian tahun baru. Sekitar abad ke-19 dalam perkembangannya, masuklah sejumlah unsur gaya musik tradisional Nusantara, seperti penggunaan seruling dan beberapa komponen gamelan.

Keroncong asli merupakan bentuk keroncong yang lebih klasik, berasal dari style gamelan Jawa dalam hal:

1. Bentuk lagu dalam da capo aria.

2. Penggantian rebab dan suling jawa sebagai pembawa melodi dengan biola dan flute. 
3. Adaptasi dari style banyu mili dari cara memainkan gambang dalam permainan gitar

\section{Continuo.}

4. Introduski dan interlude diimprovisasi, tanpa ada coda pada akhir masculine.

5. Irama motif riff dimainkan oleh ukulele.

6. Pola irama oleh cello pizzicato menirukan permainan kendangan Jawa.

7. Bass pizzicato menirukan permainan gongan yang berulang.

Sementara Gamelan Jawa mempengaruhi Keroncong Asli, Macapat membawa kita kepada bait-bait dalam Langgam Keroncong yang diperkenalkan oleh Gesang. Gaya menyanyi keroncong dengan elemen Jawa biasanya tidak ditampilkan dalam notasi, yaitu:

1. Cengkok, melodi yang dihias dari glissando dan gruppetto kepada nada yang tak Terucapkan.

2. Nggandhul, tempo dalam style menyanyi untuk mendelay bait terakhir dari iringan musik demi kenyamanan hati penyanyinya.

3. Suara sengau/hidung seperti yang dilakukan oleh penyanyi perempuan dari suku bangsa Moor yang tidak diperkenankan membuka lebar mulutnya

4. Improvisasi yang sterotype dimana pengulangan tidak pernah sama.

Selama memainkan Langgam Jawa tersebut terdapat salah satu alat musik yang memainkan pola kendangan yaitu instrumen Cello. Instrumen tersebut memberikan aksentuasi yang memberikan warna suara tersendiri dalam suatu sajiannya. Melihat fenomena yang demikian, maka menjadi suatu hal yang menarik untuk ditelaah sejauh mana dari penerapan pola permainan kendangan pada instrumen Cello dalam Keroncong.

Bentuk langgam Jawa Keroncong yang dikenal sampai sekarang ini merupakan pengembangan musik keroncong yang sudah ada seperti bentuk Stambul, Keroncong Asli dan Langgam Keroncong. Berkat kreatifitas para seniman keroncong, maka lahirlah bentuk Langgam Jawa Keroncong, karena menurut Gesang bahwa Langgam Jawa lahir tahun 1950 dengan lagu Kembang Kacang. Lagu ini pertama kali dibawakan dengan mempergunakan instrument Keroncong. Padahal biasanya dibawakan dengan mempergunakan gamelan Jawa karena memang gending karawitan Jawa. Istilah Langgam berarti gaya model dan cara permainannya khas dengan jumlah 32 birama. Pengertian Langgam Jawa Keroncong adalah jenis lagu Langgam 
yang menggunakan tangga nada pentatotnis dan menggunakan gaya permainannya dipengaruhi oleh music daerah setempat yaitu karawitan Jawa, sehingga bentuk permainan Langgam Jawa Keroncong mirip karena menirukan gamelan Jawa.

Ciri khas yang menonjol dalam Langgam Jawa Keroncong yaitu terletak pada permainan instrumen cello karena dalam bentuk permainannya menirukan kendang ciblon. Menurut fungsinya cello dalam Langgam Jawa Keroncong memegang peranan sebagai ritmis. Apabila disejajarkan dengan instrumen dalam karawitan, maka dalam karawitan Jawa diidentikan dengan instrumen kendang yang mempunyai peranan sebagai pengatur cepat lambatnya irama (pamurba irama). Berarti peranan instrumen cello sama dengan instrumen kendang yang berperan sebagai pemegang irama yang mempunyai wewenang untuk mebawa arah lagu yang akan dibawakan seperti mempergunakan irama engkel atau dobel, atau dalam karawitan disebut dengan weled dan rangkep. Oleh karena itu seorang pemain cello akan lebih bagus jika mengetahui teknik permainan kendang ciblon, motif sekaran, pola kendangan yang nantinya diterapkan dalam permainan cello pada Langgam Jawa Keroncong.

Permasalahan yang muncul dalam masyarakat, banyak pemain cello sangat terampil memainkan instrumen cello dalam irama Keroncong, tetapi ketika memainkan Langgam Jawa terdengar kurang enak. Hal ini kemungkinan disebabkan pemain cello kurang memahami aspekaspek permainan kendang ciblon dalam karawitan Jawa. Mengingat pola permainan cello dalam Langgam Jawa Keroncong merupakan bentuk permainan yang menirukan pola permainan kendang ciblon antara lain tentang warna suara, irama, motif sekaran, andegan, dan buka. Melihat fenomena tersebut, maka sesuatu yang menarik untuk dijadikan aspek dalam penelitian ini yaitu sejauhmana teknik permainan cello dalam Langgam Jawa Keroncong.

\section{Musik Keroncong dan Langgam Jawa}

Langgam Jawa merupakan jenis keroncong hasil dari perkembangan jenis langgam, hal ini karena di daerah Jawa Tengah musik keroncong berkembang pesat hingga pada akhirnya berkembang menjadi campursari. Improvisasi permainan cello dalam langgam Jawa lebih menyerupai kendang Jawa. Kemiripan tersebut lebih terasa lagi dalam keroncong langgam Jawa dan tidak jarang dalam permainannya sering dimainkan pula teknik yang disebut "kepla'an". Improvisasi permainan cello keroncong langgam Jawa yang biasa 
dimainkan oleh grup-grup keroncong tentunya berbeda-beda, hanya sedikit grup keroncong yang dalam improvisasi cellonya terdapat kemiripan dengan permainan kendang Jawa atau ciblon.

Selain gaya permainan, pada musik keroncong terdapat pula jenis-jenis keroncong. Sejak pertengahan abad ke-20 telah dikenal paling tidak tiga macam keroncong. Bagi pemusik yang sudah memahami alurnya, mengiringi lagu-lagu keroncong sebenarnya tidaklah susah, sebab cukup menyesuaikan pola yang berlaku. Pengembangan dilakukan dengan menjaga konsistensi pola tersebut. Selain itu, terdapat pula bentuk-bentuk campuran serta adaptasi. Jenis-jenis keroncong tersebut antara lain sebagai berikut:

\section{Keroncong asli}

Keroncong asli adalah bentuk lagu yang dimana harmoni dan pergerakan akornya mempunyai susunan yang sudah baku (pakem) serta jumlah bar yang baku yaitu dua puluh delapan bar. Pergerakan akor keroncong asli adalah sebagai berikut :

I - - - I - - - V - - - V - - -

II - - - II - - - V - - - V - - (permulaan/intro)

V - - - V - - - (miden spel, semacam bridge yang hanya berisi musik)

IV - - - IV - - - IV - - - IV - V - I - - - I - - - (ole-ole atau yang sering disebut reff)

$\mathrm{V}$ - - - V - - - I - - - IV - V -

I - - - IV - V - I - - - I - - -(senggaan yang biasa dipakai sebagai intro)

V - - - V - - - I - - - I (IV - I -) (apabila dimainkan dua kali)

Keroncong asli terkadang juga diawali oleh voorspel terlebih dahulu. Voorspel adalah seperti intro yang mengarah ke nada/chord awal lagu, yang dilakukan oleh alat musik melodi seperti biola, flute, atau gitar. (Lilik, 2008: 3 ).

\section{Langgam}

Langgam memiliki susunan bar yang terdiri dari tiga puluh dua bar. Pergerakan akor pada langgam adalah sebagai berikut :

I - - - IV - V - I - - - I - - - 
V - - - V - - - I - - - I - - - (syair/bait I)

I - - - IV - V - I - - - I - - -

V - - - V - - - I - - - I - - - (syair/bait II)

IV - - - IV - - - I - - - I - - -

II7 - - -II7 - - - V - - - V - - - (reff)

I - - - IV - V - I - - - I - - -

V - - - V - - - I - - - I - - - (pengulangan lagu bait II)

Bentuk adaptasi keroncong terhadap tradisi musik gamelan dikenal sebagai langgam jawa, yang berbeda dari langgam yang dimaksud di sini. Langgam Jawa memiliki ciri khas pada penambahan instrumen antara lain Siter, kendang (bisadiwakili dengan modifikasi permainan cello ala kendang), saron, dan adanya bowo atau suluk berupa intro vokal tanpa instrumen untuk membuka sebelum irama dimulai secara utuh. (Lilik, 2008: 3 ).

\section{Stambul}

Stambul merupakan jenis keroncong yang namanya diambil dari bentuk sandiwara yang dikenal pada akhir abad ke-19 hingga paruh awal abad ke-20 di Indonesia dengan nama komedi stambul. Nama "stambul" diambil dari Istambul Turki. Untuk bentuk Stambul ini ada dua macam penyebutannya yaitu Stambul I dan Stambul II. Pebedaannya terletak pada jumlah barnya, pada Stambul I terdiri dari 16 bar sedangkan pada Stambul II terdiri dari 32 bar. Pergerakan akor pada Stambul I dan II:

Stambul I:

IV - - - IV - - - I - - - I - -

V - - - V - - - I - - - I - - - (lagu bagian pertama)

IV - - - IV - - - I - - - I - - -

V - - - V - - - I - - - I - - - (pengulangan) (Lilik, 2008: 3 ).

Biasanya dalam lagu Stambul I ini liriknya berupa pantun.

Stambul II:

(I - - - I - - -) IV - - - IV - - -

IV - - -IV - V - I - - - IV - V - (lagu bagian pertama) 
I - - - I - - - - - - -

V - - - V - - - IV - V - (lagu bagian kedua)

I - - - I - - IV - - -IV - - -IV - - -

IV - V - I - - - IV - V - (pengulangan pertama)

I - - - I - - - V - - - V - - -

V - - - V - - - I - - - I (IV - V -) (pengulangan kedua), Lilik (2008 : 3)

Stambul diawali oleh penyanyi itu sendiri, atau intro lagu bukan dari alat musik melainkan dari penyanyi tanpa iringan instrumen terlebih dahulu. Lagu jenis Stambul ini berkembang di Jawa Timur dengan adanya teater rakyat komedi Stambul dengan menggunakan lagu-lagu keroncong di atas panggung pertunjukan sebagai selingan maupun bagian dari drama itu sendiri.

\section{Instrumen Cello Dalam Langgam Jawa}

Cello adalah sebuah instrumen yang rumit yang terdiri atas banyak bagian. Meskipun pada umumnya cello dibuat dari kayu, namun beberapa bagiannya dapat dibuat dari baja atau logam-logam lainnya. Dawai-dawai modern dibuat dari baja, usus, nilon atau bahan-bahan inti sintetis lainnya, yang dilapisi dengan berbagai gulungan logam. Kerangka utama cello biasanya dibuat dari kayu, meskipun beberapa cello modern dibuat dari bahan serat karbon. Sebuah cello tradisional biasanya mempunyai bahan atas dari kayu spruce, dengan maple untuk bagian belakang, sisi, dan lehernya. Kayu-kayu yang lain, seperti poplar atau willow, kadang-kadang digunakan untuk bagian belakang atau sisinya. Cello yang lebih murah seringkali bagian atas dan belakangnya dibuat dari kayu lapis. Cello-cello berukuran standar disebut "ukuran penuh". Namun ada pula cello dengan ukuran-ukuran yang lebih kecil, dari yang "tujuh-perdelapan" dan "tiga-perempat" hingga "seperenambelas".

Langgam Jawa merupakan bentuk adaptasi musik keroncong ke dalam musik tradisional Jawa, khususnya gamelan. Genre ini masih dapat digolongkan sebagai keroncong. Tokoh-tokoh musik ini di antaranya Andjar Any, Gesang, dan Ki Narto Sabdo. Penyanyi yang dapat disebut legendaris dari genre musik ini adalah Waljinah. Beberapa lagu langgam Jawa sangat popular dan dikenal hampir setiap orang di wilayah berbahasa 
Jawa, seperti: Gambang Suling (ciptaan Ki Narto Sabdo), Yen Ing Tawang (ciptaan Andjar Any), Caping Gunung (ciptaan Gesang, 1973), Jenang Gula (ciptaan Andjar Any), Jangkrik Genggong (ciptaan Andjar Any), Pamitan (ciptaan Gesang), dan Aja Lamis (ciptaan Gesang).

Instumen cello keroncong tentunya memiliki bentuk yang sama dengan cello gesek pada umumnya, namun terdapat perbedaan dari jumlah senar, bahan senar dan cara memainkannya. Jumlah senar pada cello gesek menggunakan 4 buah senar sementara pada cello keroncong hanya menggunakan 3 buah senar. Senar cello keroncong memiliki susunan D - G - d. Selain itu dari bahan senar yang digunakannya berbeda, pada instrumen cello gesek menggunakan senar yang terbuat dari logam atau baja, sementara cello keroncong tebuat dari bahan nilon. Cara permainannya pun terdapat perbedaan dengan cello gesek. Cello gesek diamainkan dengan cara digesek menggunakan alat yang di sebut Boo, sedangkan cello keroncong dimainkan dengan cara dipetik atau Pizzicato. Dalam permainan instrumen cello keroncong, terdapat beberapa jenis pola irama, dimana pola irama tersebut memiliki pola yang berbeda beda tentunya. Pola irama yang biasa dimainkan oleh pak Ahmad selaku pemain Cello Orkes Keroncong Harmoni adalah sebagai berikut.

\section{Irama Engkel}

2. Irama Dobel

3. Irama Petikan

4. Irama Kentrungan

Irama jenis langgam Jawa pada musik keroncong sangat erat kaitannya dengan pola kendangan, karena bisa dikatakan instrumen cello keronconglah yang mendominasi pada irama jenis ini. Pola kendangan yang terdapat pada irama jenis langgam Jawa di musik keroncong ini lebih mendominasi, karena pada dasarnya irama jenis ini hampir di semua alat musiknya mengacu pada musik karawitan yang juga didominasi oleh kendang jawa. Oleh karena itu pada permainan cello di irama jenis langgam Jawa muncul satu teknik yang dimaksudkan agar mirip dengan suara kendang jawa. Teknik tersebut sering di sebut teknik "kepla'an". Cara memainkan teknik ini yaitu dengan memukulkan telapak tangan pada cello keroncong agar cello keroncong dapat berbunyi dengan suara "pak" seperti layaknya salah satu suara dari kendang Jawa. Teknik "kepla'an" jika digabungkan dengan nada dan ritmis pada cello keroncong yang dimiripkan juga dengan pola kendang Jawa, akan menjadi satu teknik baru yang dinamakan teknik 
kendangan. Teknik kendangan hanya merupakan istilah dalam permainan instrumen musik cello keroncong yang berkembang dikalangan para musisi dan pemerhati musik keroncong. Teknik permainannya menyerupai instrumen kendang, tetapi ritmiknya tidak sama dengan kendang. Sekalipun tidak sama dalam teknik permainannya dengan kendang Jawa, tetapi ada sedikit kemiripan dalam pola ritmisnya dengan ciblon, mungkin hal ini dikarenakan keroncong berkembang pesat di daerah Jawa, khususnya Jawa Tengah, sehingga muncul istilah di kalangan para musisi dan pengamat musik keroncong teknik "kendangan".

Teknik kendangan pada instrumen musik cello keroncong memiliki ragam motif permainan, tidak ada yang baku. Setiap pemain cello memiliki gaya atau teknik sendiri. Dalam permainannya, pola ritmik cello tidak selalu sama tiap bar. cello dimainkan dengan berimprovisasi sesuai dengan gaya permainnannya masing-masing. Hal ini pulalah yang menyebabkan dalam setiap dalam pementasan musik keroncong untuk instrumen cello tidak pernah menggunakan partitur lengkap, sekalipun cello alat melodis, sekalipun dibuatkan partitur lengkap jarang sekali ada pemain cello keroncong yang bermain sesuai not-not yang ada dalam partitur tersebut. Kondisi seperti ini lebih dikarenakan cello dimainkan dengan improvisasi dan teknik dari masing-masing pemainnya. Adapun contoh pola ritmik kendangan instrumen cello keroncong seperti di bawah ini.

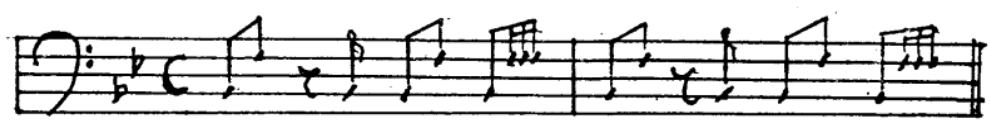

Permainan cello keroncong dalam mengiringi lagu yang dimainkan dengan bebas, seperti tidak ada pola tertentu yang menjadi acuannya atau dengan kata lain dimainkan dengan improvisasi. Improvisasi tersebut lebih terasa ketika cello keroncong mengiringi lagu-lagu keroncong langgam Jawa, dengan istilah teknik kendangan.

Di dalam pola kendangan pada cello terdapat satu teknik yang dinamakan teknik kepla'an. Teknik kepla'an adalah bagian dari teknik kendangan instrumen musik cello keroncong. Teknik ini dimainkan dengan cara memukul bagian tubuh cello dengan tangan terbuka, tetapi ada saja beberapa pemain cello keroncong yang memukul bagian 
lidah cello, dan hal itu merupakan teknik yang kurang tepat. Teknik kepla'an ini menghasilkan bunyi "tak", bahkan ada juga beberapa pemain cello yang menggunakan aksesoris cincin pada tangan kanannya guna menghasilkan bunyi dari teknik kepla'an yang cukup keras dan sebenarnya hal tersebut pun kurang tepat karena secara tidak langsung dapat merusak, baik bagian tubuh maupun lidah cello tersebut.

Dari beberapa banyak suara yang dihasilkan oleh kendang Jawa, Cuma tiga jenis suara saja yang diterapkan pada Cello keroncong. Suara itu adalah "tak", "ket", "lung" "dung" atau "deng", "dang", "det", dan "tung". Suara "tak" dihasilkan dari teknik kepla'an , suara "ket" dihasilkan dari suara harmonik, dan suara "tung" dihasilkan dengan memetik senar biasa pada Cello. Sedangkan dalam penggunaannya, suara "tak" kadang juga di bunyikan bersama dengan suara "tung", sehingga terjadi suara "tak + tung". Secara lebih jelasnya dalam menghasilkan warna suara tersebut yaitu sebagai berikut:

1. Teknik pukulan untuk menghasilkan suara "ket" yaitu dengan memetik tali pertama dengan mempergunakan jari tangan kanan, sedangkan jari tangan kiri tidak terlalu menekan tali tersebut sehingga akan menghasilkan warna suara yang tertahan yaitu "ket"

2. Teknik pukulan cello untuk menghasilkan suara "tak" ialah dengan cara memukulkan empat jari tangan kanan pada badan cello bagian atas, dengan catatan memukulnya agak lentur, sebab apabila terlalu keras memukulnya dapat mengakibatkan cello pecah.

3. Teknik pukulan untuk menghasilkan suara "tung" yaitu dengan memetik tali pertama dengan mempergunakan ibu jari tangan kanan, sedangkan jari tangan kiri menekan tali tersebut dengan mantap agar suara tidak tertahan dan dapat nyaring.

4. Teknik pukulan untuk menghasilkan suara "lung" yaitu dengan cara memetik tali pertama dengan mempergunakan jari telunjuk, sedangkan jari tangan kiri menenkan tali tersebut dengan mantap agar suara tidak tertahan. Biasanya suara "lung" merupakan kelanjutan atau sebagai variasi pukulan dari suara "tung" sehingga menjadi suara "tu-lung". Kadang-kadang pukulan ini dibuat triol (pukulan tiga) akhirnya menjadi suara "tu-lung-tung"

5. Teknik pukulan untuk menghasilkan suara "dung" atau "deng" yaitu dengan cara memetik tali kedua atau ketiga dengan mempergunakan ibu jari tangan kanan, sedangkan jari tangan kiri menekan tali tersebut dengan mantap agar suara tidak tertahandan dapat los.

6. Teknik pukulan untuk menghasilkan suara "dang" yaitu dengan cara memetik tali kedua dengan mempergunakan ibu jari tangan kanan, sedangkan jari tangan kiri menekan tali tersebut 
dengan mantap agar secara tidak tertahan dan dapat los atau nyaring. Dengan catatan sewaktu memetik tali kedua harus bersama-sama dengan pukulan suara "tak" atau keplakan pada badan cello bagian atas.

7. Teknik pukulan untuk menghasilkan suara "det" yaitu dengan cara memetik tali kedua dengan mempergunakan ibu jari tangan kanan, sedangkan jari tangan kiri tidak terlalu menekan tali tersebut agar suara agak tertahan. Pada saat ibu jari kanan memetik tali cello harus bersama-sama dengan menekan mempergunakan telapak tangan atau dipathet (Jawa) sehingga menghasilkan suara yang agak tertahan dan rasanya mati yakni suara "det".

\section{Penyetemen Instrumen Cello}

Teknik penyetemen instrument Cello memerlukan perasaan yang tajam karena berhubungan dengan solfegio atau titi laras (Jawa). Rasa yang diinginkan sudah enak apa belum maka harus disesuaikan dengan apa yang diinginkan. Jadi masalah penyeteman atau laras tidaklah mudah, karena hal ini menyangkut masalah harmoni atau keselarasan bunyi. Dalam instrument Cello mempergunakan tiga senar yang terbuat dari barahan nilon. Adapun urutan nada pada setiap senar tersebut adalah sebagai berikut;

1. Senar pertama stem nada D kecil.

2. Senar kedua stem nada B besar.

3. Senar ketiga stem nada $\mathrm{C}$ besar.

Steman tersebut dapat pula berubah untuk mempermudah dalam posisi permainannya dengan steman sebagai berikut:

1. Senar pertama stem nada D kecil.

2. Senar kedua stem nada $G$ besar.

3. Senar ketiga stem nada D besar.

\section{Pola Permainan Cello Dalam Langgam Jawa}

Irama jenis langgam Jawa, tentunya hampir sama dengan irama keroncong pada umumnya jika dilihat dari pola iramanya, di dalam irama jenis langgam Jawa juga terdapat irama engkel dan irama dobel, hanya saja istilahnya berbeda. Pada 
langgam Jawa irama engkel disebut mlampah dan irama dobel disebut dados. Di dalam irama jenis langgam Jawa, cello juga berfungsi sebagai pengatur tempo lagu mulai dari awal hingga akhir.

Dalam penerapan irama jenis langgam Jawa juga terdapat suatu pola penghubung antara irama mlampah dan irama dados, hal ini dimaksudkan untuk menjembatani dua pola irama yang memiliki jatah tempo yang berbeda sehingga terkesan enak untuk di dengarkan. Karena pada dasarnya tempo dari pola irama lampah lebih cepat dari pola irama dados. Hanya saja nada dan ritmis pada irama dados dimainkan dua kali lipat dari irama mlampah, sehingga terkesan irama dados lebih cepat temponya, padahal justru lebih lambat temponya dibandingkan dengan irama mlampah.

Pola permainan yang dipakai dalam permainan cello keroncong, diambil dari polapola permainan kendhang ciblon saat memainkan langgam Jawa. Walaupun diambil dari pola permainan kendhang ciblon, sesungguhnya pola permainan cello keroncong tidak memiliki patokan yang baku. Pemain biasanya berimprovisasi sesuai imajinasinya dan membuat pola-pola permainan sendiri agar bisa menyamai pola permainan kendhang Jawa. Bahkan, dari beberapa pemain ada yang menirukan sama persis seperti pola yang dimainkan kendhang ciblon dalam lagu langgam Jawa, sehingga pola permainannya bisa dikatakan sama seperti kendhang Jawa.

Langgam Jawa pada umumnya ber irama 4/4, dan susunan biramanya terdiri dari 32 bar yang terbagi antara 4 bagian yaitu bagian A untuk bait pertama ; Bagian $\mathrm{A}^{\prime}$ untuk bait kedua ; bagian B disebut Refrein ; bagian A' untuk bait terakhir. Pada bagian $\mathrm{A}$ atau bait pertama dan bagian $\mathrm{A}^{\prime}$ atau bait kedua diisi oleh irama engkel dalam permainan langgam Jawa. Bagian $B$ disebut juga dengan Refrein, pada bagian ini terjadi peralihan irama dari irama engkel ke irama dobel. Pada peralihan irama tersebut, tempo melambat atau disebut juga dengan ritardando kemudian pada birama selanjutnya kembali lagi ke tempo awal dan sekaligus masuk ke pola irama dobel. Pola irama dobel disebut juga dengan pola irama rangkap, yaitu pola permainan yang pada waktu engkel memainkan notasi yang nilai nya $1 / 2 \quad$ menjadi $1 / 4$. Jadi pola permainan cello menjadi lebih cepat dari irama engkel tetapi dengan tempo yanga sama. 
Dalam permainannya langgam Jawa juga tidak mengenal akor, sehingga instrumen dalam langgam Jawa hanya bermain mengikuti melodi lagu. Berikut ini adalah contoh pola permainan cello keroncong dalam lagu langgam Jawa Yen Ing Tawang Ono Lintang.
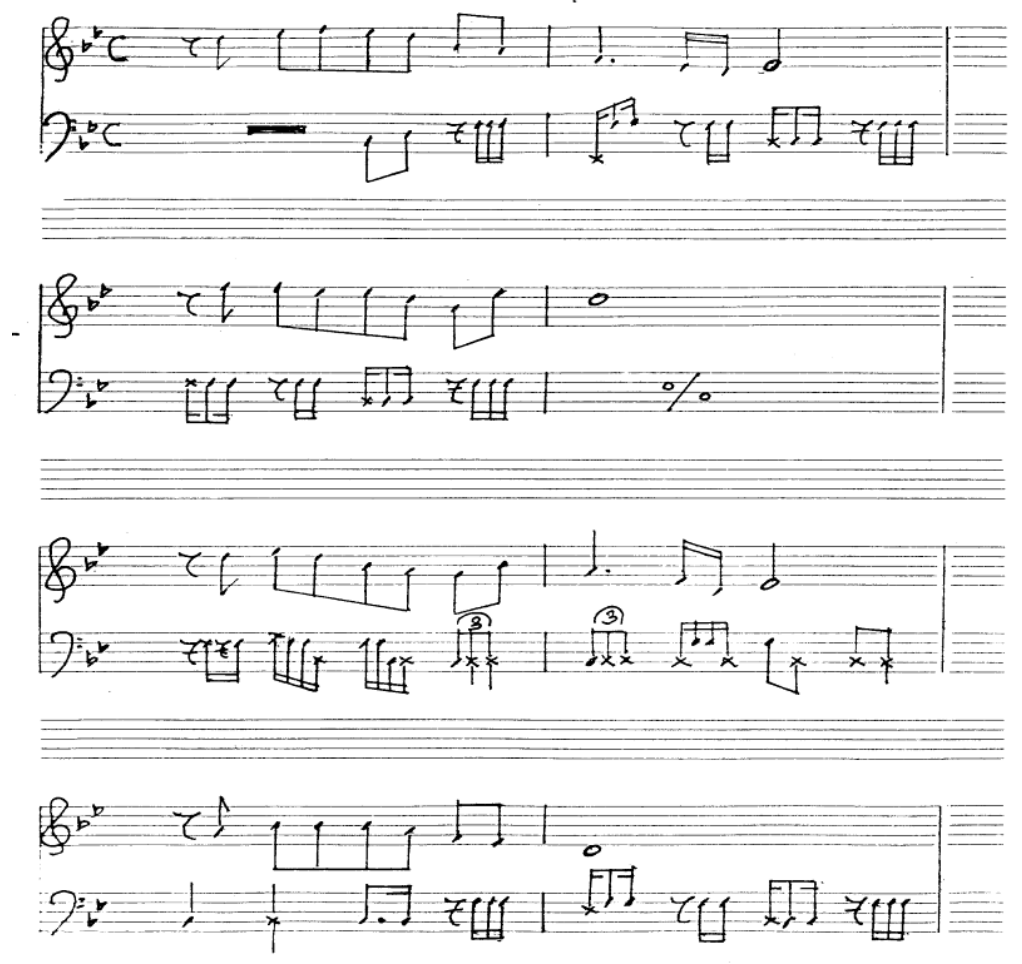

Pada partitur di atas adalah pola permainan cello keroncong dalam lagu langgam Jawa yang mengimitasi pola permainan pada kendhang ciblon. Pola tersebut setelah dianalisis ternyata dalam permainannya diikuti oleh nada-nada yang dimainkan secara bersamaan dengan pola permainan dalam lagu langgam Jawa. Di bawah ini adalah keterangan dan simbol dari pola permainan lagu langgam Jawa.

a) Dah : bunyi tersebut terletak pada nada $G$ dalam cello keroncong

b) Den : bunyi tersebut terletak pada nada B dalam cello keroncong yang

c) Det : bunyi tersebut terletak pada nada D1 dalam cello keroncong

d) Tung : bunyi tersebut terletak pada nada G1 dalam cello keroncong

e) Lung : bunyi tersebut terletak pada nada G1 dalam cello keroncong sama dengan bunyi tung, hanya cara membunyikan saja yang berbeda.

f) Ket : bunyi tersebut terletak pada nada G1 sama seperti posisi di bunyi thung dan lung, hanya cara membunyikan yang berbeda. 
g) Tak : bunyi tersebut adalah bunyi yang tidak memiliki nada, sehingga dalam penulisanya hanya ditulis simbol pada nada $\mathrm{B}$.

h) Dang : bunyi tersebut adalah gabungan antara bunyi den dan tak terletak pada nada $B$.

\section{Kesimpulan}

Langgam Jawa pada umumnya memiliki kesamaan dengan langgam keroncong, tetapi perbedaanya terletak pada instrumen siter yang diwakili oleh cak, dan instrumen kendhang yang diwakili oleh cello. Langgam Jawa pada umumnya berirama 4/4, dan susunan bar umumnya terdiri dari 32 bar yang terbagi dalam empat bagian yaitu bagian A untuk bait pertama ; bagian A untuk bait kedua; bagian B disebut Refrein; bagian A untuk bait terakhir. Jadi kebanyakan dalam langgam Jawa, intronya diambil dari empat birama terakhir dari lagu langgam tersebut.

Dalam permainan langgam Jawa, terdapat dua pola permainan yaitu pola permainan engkel dan dobel, dalam kedua pola permainan tersebut terdapat bunyi-bunyi yang dimainkan antara lain bunyi dah, den, det, tung, lung, ket, tak, dan dlang. Produksi bunyi cello keroncong dalam pola permainan lagu langgam Jawa dimainkan dengan cara memukul bodi cello dan juga memetik senar cello keroncong dengan menggunakan jari-jari tangan dan dipadukan dengan nada-nada yang diambil dari tangga nada yang dipakai dalam langgam Jawa. Dalam memproduksi bunyi-bunyi yang dihasilkan cello keroncong dalam langgam Jawa, ada bunyi-bunyi yang cara memproduksinya tidak menggunakan nada dan ada juga bunyi yang menggunakan nada. Diantara bunyi yang tidak menggunakan nada yaitu bunyi tak, dan bunyi yang memiliki nada yaitu bunyi dhah, den, det, tung, lung, ket, dan yang terakhir yaitu bunyi dlang bunyi ini termasuk gabungan bunyi bernada dan tak bernada dan dalam penggabunganya bunyi ini digolongkan sebagai bunyi yang bernada (memiliki nada).

Improvisasi pada instrumen Cello pada irama jenis langgam Jawa merupakan adaptasi bunyi dari permainan kendang Jawa. Hal ini dikarenakan musik keroncong berkembang pesat di daerah Jawa khususnya Yogyakarta dan Jawa Tengah. Selain itu karena adanya motivasi para seniman Indonesia khususnya seniman keroncong untuk melestarikan musik karawitan yang diaplikasikan pada jenis musik keroncong. 


\section{Daftar Pustaka}

Andriessen, 1965, Hal Ihwal Musik, terjemahan J.A. Dungga, Pradnja Paramita, Jakarta.

Anselm Strauss dan Juliet Corbin, 2003. Dasar-dasar Penelitian Kualitatif. Yogyakarta: Pustaka Pelajar.

Budiman BJ, 1979. Mengenal Keroncong Dari Dekat, Jakarta: Lembaga Kesenian Jakarta.

Creswel, John W. 2012. Research Design Pendekatan Kualitatif, Kuantitatif, dan Mixed. Yogyakarta: Pustaka Pelajar.

Dharma. 2001. Menggugat Republik Keroncong, Bandung: Gedung Indonesia Menggugat.

Edmund Husserl, 1967. The Paris Lectures, The Hargue: Martinus Nijhoff.

Harmunah, 1987. Musik Keroncong, Yogyakarta: Pusat Musik Liturgi.

Hardjana, Suka. 2008. Menggugat Republik Keroncong, Bandung: Gedung Indonesia Menggugat.

Hartoko, Dick., 1994. Manusia dan Seni, Yogyakarta: Kanisius.

Irawati. 1987. Musik Keroncong, Yogyakarta: Pusat Musik Liturgi.

Jascee, Lilik. 2008. "Musik Keroncong Punya Siapa”, dalam Majalah Tjroeng, Edisi November, Bandung.

Kayam, Umar, 1981, Seni, Tradisi, Masyarakat, Sinar Harapan, Jakarta.

Koentjaraningrat, 1986. Pengantar Antropologi, Jakarta: Aksara Baru.

Mamannoor. 2002. Wacana Kritik Seni Rupa Indonesia, Bandung: Nuansa.

Mark, Dieter., 1995. Apresiasi Musik Popular. Yogyakarta: PML.

Maryanto, M. Dwi. 2006. "Metodologi Penciptaan Seni”, jurnal Surya Seni, Vol.2 No.1, September .

Martopangrawit, R.L. 1975. Pengetahuan Karawitan Jilid I dan Pengetahuan Karawitan Jilid II. Surakarta: ASKI. 
Merriam, Alan P., 1964, The Anthropology of Music, North Western University Press, Chicago.

Moleong, Lexy J. 2010. Metodologi Penelitian Kualitatif. Bandung : Remaja Rosdakarya.

Nakagawa, Shin. 2000. Musik dan Kosmos. Jakarta: Yayasan Obor Indonesia.

Rahayu Supanggah, 2002. Bothekan Karawitan I. Jakarta: Ford Foundation \& Masyarakat Seni Pertunjukan Indonesia.

2009. Bothekan Karawitan II Garap. Program Pascasarjana bekerja sama dengan ISI Press Surakarta.

RM. Soedarsono, 1999. Metodologi Penelitian seni Pertunjukan dan Seni Rupa. Bandung: UPI.

Shinsu, Tjok. 1934. Serba Serbi Keroncong, Jakarta : Ok Indah Sari.

Soeharto AH, et. al., 1996. Serba-Serbi Keroncong, Jakarta: Musika.

Sopaheluwakan. 2008. Menggugat Republik Keroncong, Bandung: Gedung Indonesia Menggugat.

Sugiyono. 2011. Metode Penelitian Kuantitatif, Kualitatif dan R\&D. Bandung : Alfabeta. 2007. Metode Penelitian Kuantitatif, Kualitatif dan R\&D. Bandung : Alfabeta.

Supanggah, Rahayu. 2002. Botekan Karawitan 1. Jakarta: Ford Foundation dan Masyarakat Seni Pertunjukan Indonesia. 